\title{
6
}

\section{LA RESOLUCIÓN DEL PROBLEMA DE LOS PRÉSTAMOS MOROSOS EN ESPAÑA Y EN LA UNIÓN EUROPEA}

La crisis financiera que estalló en el año 2007 y el lento crecimiento económico posterior generaron un elevado volumen de préstamos morosos (non-performing loans, NPLs) en las entidades europeas. Estos no solo afectan a la rentabilidad individual de las entidades, sino también a la estabilidad financiera y al crecimiento económico real. Este artículo recoge las principales medidas adoptadas en la resolución del problema de los NPLs en España y en la Unión Europa. En ambos casos las medidas persiguen tres objetivos fundamentales: la correcta identificación y la valoración de los NPLs por las entidades de crédito, la mejora de la eficiencia de los marcos concursales y el desarrollo del mercado secundario de NPLs.

Palabras clave: préstamos dudosos, provisiones, marco concursal, sociedad de gestión de activos. Clasificación JEL: G14, G21, K22.

\section{Caracterización del problema}

\section{1. ¿Qué son los NPLs?}

La actividad bancaria consiste fundamentalmente en transformar un input con forma de fondos con obligación de ser devueltos a muy corto plazo en un output con forma de fondos con obligación de ser devueltos a más largo plazo. Durante este proceso de transformación de vencimientos suele surgir un residuo, los préstamos morosos o impagados. Aunque la aparición de este subproducto es casi inevitable, no es menos cierto que los préstamos morosos (non-performing loans, NPLs) son más abundantes cuanto menos prudente es la política de concesión de crédito o en las fases recesivas del ciclo económico.

\footnotetext{
* Técnico Comercial y Economista del Estado. Versión de julio de 2018.
}

La Autoridad Bancaria Europea (EBA) define los préstamos y créditos dudosos (non-performing exposures, NPEs) como aquellos en los que el deudor acumula más de 90 días de retraso en los pagos (préstamos morosos o NPLs) o aquellos con retrasos inferiores en los que el pago completo de la deuda no se considera posible sin recurrir a la ejecución de las garantías (dudosos subjetivos o unlikely to pay, UTPs).

\subsection{Situación en España y en la Unión Europea}

Según los datos del Boletín Estadístico del Banco de España ${ }^{1}$, en abril de 2018 el sistema bancario español, entendido este como el $\triangleright$

\footnotetext{
1 https://www.bde.es/webbde/es/estadis/infoest/a0403.pdf
} 
conjunto de entidades de crédito autorizadas en España, mantenía en su balance un volumen bruto de NPLs de 82.635 millones de euros y presentaba una ratio de morosidad del 6,77 por 100 . Estos datos no tienen en cuenta la actividad bancaria realizada por las filiales de entidades de crédito españolas en otros países. Análogamente, los datos incluyen la actividad crediticia de las filiales de entidades de crédito extranjeras que operan con licencia bancaria obtenida en España.

Las entidades de crédito españolas mantenían a nivel consolidado, es decir, teniendo en cuenta el negocio desarrollado por sus filiales fuera de España, un volumen de NPLs de 103 millardos de euros en marzo de 2018, según los datos del Risk Dashboard de la EBA $^{2}$. De este modo, las entidades españolas ostentan el 13,2 por 100 de los 779,2 millardos de euros de NPLs que acumulaban las entidades de crédito de la UE. España sería el tercer país con mayor volumen de préstamos morosos, superado por Italia (179,6 millardos de euros) y Francia $(121,6$ millardos de euros).

Sin embargo, cuando se tiene en cuenta la ratio de NPLs brutos sobre el crédito bruto total, la ratio española se sitúa muy próxima a la ratio media de la UE (4,5 por 100 vs. 3,9 por 100) y por debajo incluso de la media de la eurozona $(4,9 \text { por } 100)^{3}$. En términos relativos son especialmente significativas las ratios de Grecia (45,3 por 100$)$, Chipre (38,9 por 100$)$, Portugal (13,6 por 100) e Italia (10,8 por 100). Por el contrario, las ratios de NPLs son insignificantes en Luxemburgo (0,8 por 100), Suecia (1 por 100) o Finlandia (1,3 por 100).

2 http://www.eba.europa.eu/documents/10180/2282718/ Risk+Dashboard+-+data+as+of+Q1+2018.pdf

3 https://www.bankingsupervision.europa.eu/ecb/pub/pdf/ssm. supervisorybankingstatistics_fourth_quarter_2017_201804.en.pdf
Estos datos, si bien pueden considerarse elevados aún, son significativamente inferiores a los máximos alcanzados algunos años atrás. La tasa de morosidad española para el negocio doméstico alcanzó su máximo histórico del 13,6 por 100 en diciembre de 2013. Para comprender la magnitud del esfuerzo de reducción de NPLs debe tenerse en cuenta que, desde esa fecha, el denominador de la ratio (el volumen agregado de crédito doméstico) se ha reducido un 15,8 por 100 . Por su parte, el numerador se ha reducido un 58,1 por 100 desde los máximos absolutos alcanzados en enero de 2014 (197.276 millones de euros).

A nivel consolidado, la ratio de NPLs española alcanzó su máximo en diciembre de 2013 cuando alcanzó el 8,9 por 100, mientras que la ratio de la UE tocó techo en diciembre de 2014 al situarse en el 6,5 por 100.

\section{3. ¿Por qué son los NPLs un problema?}

Elevadas ratios de NPLs suponen problemas para la rentabilidad bancaria y la estabilidad financiera que, además, tienen implicaciones de carácter macroeconómico.

Una entidad con un alto volumen de NPLs no solo se encontrará con que su pasivo está financiando unos activos que no generan ningún flujo de caja y cuyas probabilidades de recuperar la totalidad del valor nominal son limitadas, sino que, además, deberá incurrir en mayores provisiones y elevados costes de gestión (reclamación de deudas, ejecución de garantías, adecuación, mantenimiento y venta de los activos adjudicados, etcétera).

Por otro lado, los NPLs suponen un mayor consumo de capital regulatorio para las entidades al recibir una mayor ponderación por $\square$ 
riesgo en la determinación de los requerimientos de capital que los créditos performing así como por los mayores requerimientos que los supervisores exigen a aquellas entidades cuyos balances presentan un mayor riesgo (Pilar 2).

Adicionalmente, las entidades con unas elevadas ratios de NPLs pueden generar dudas acerca de su viabilidad o de su rentabilidad futura que dificulten su acceso a la financiación, sobre todo, en los mercados de capitales.

Por tanto, la capacidad de una entidad con elevados volúmenes de NPLs para generar capital tanto de forma orgánica (acumulación de beneficios no distribuidos) como inorgánica (ampliaciones de capital) será escasa. De este modo, se encontrará en una débil posición para soportar episodios de tensión en los mercados financieros.

Si la entidad es de un tamaño significativo o presenta importantes interconexiones con otras entidades de crédito o infraestructuras de mercado, las dificultades podrían propagarse al resto del sistema financiero, afectando así a la estabilidad financiera.

Por último, una elevada presencia de NPLs puede tener implicaciones de carácter macroeconómico debido a sus efectos en la oferta y en la demanda de crédito.

Los NPLs obligan a las entidades de crédito a asignar liquidez y capital a actividades improductivas a la vez que la generación de recursos disminuye. De esta manera, se reduce el espacio en los balances de los bancos para conceder nuevo crédito.

Por otra parte, muchas entidades suelen hacer un mal uso de las reestructuraciones de créditos. Los préstamos concedidos a empresas inviables suelen ser refinanciados una y otra vez con objeto de evitar el reconocimiento de una pérdida que en el momento presente la entidad tendría dificultades para asumir. De este modo, el crédito es asignado de una forma poco eficiente.

Además, los prestatarios de NPLs que no han sido cancelados o adecuadamente reestructurados cuentan con pocos incentivos para solicitar financiación para acometer nuevos proyectos empresariales incluso cuando estos son perfectamente viables. Ello se debe a una asimetría en el reparto último de los riesgos de los proyectos. Así, si el proyecto fracasa, la empresa verá incrementada su posición deudora con la entidad. Sin embargo, si el proyecto resulta exitoso, una porción significativa de los beneficios deberán destinarse a la cancelación de las deudas existentes.

\section{Políticas adoptadas para abordar el problema de los NPLs}

Una adecuada identificación del volumen de NPLs y una correcta valoración del importe recuperable deben constituir el primer paso en la resolución del problema de los NPLs. Para ello, la contabilidad bancaria debe ser un fiel reflejo de su situación.

Sin embargo, las normas contables resultan en ocasiones poco específicas al estar basadas en principios generales y algunas entidades, temerosas de que un elevado volumen de provisiones las obligue a registrar unas pérdidas tales que comprometan sus recursos propios, posponen el reconocimiento del deterioro de valor de los NPLs.

Así pues, la adecuada identificación y valoración de los NPLs debe ser revisada a través de inspecciones periódicas o a través de ejercicios exhaustivos de revisión de la calidad de los activos (asset quality reviews, AQRs).

Una vez que los NPLs han sido identificados y correctamente valorados, la entidad $\triangleright$ 
debe decidir si llega a un acuerdo con el acreedor para reestructurar sus deudas o si, por el contrario, resulta más adecuado cancelar el préstamo mediante la ejecución de las garantías asociadas o solicitando el concurso del deudor. En cualquier caso, cuanto más eficiente sea el marco concursal con mayor facilidad se desharán las entidades de sus NPLs y mayor será el importe recuperable.

Las entidades de crédito cuentan con un gran conocimiento de sus clientes, lo que les permite elegir acertadamente la solución legal que maximiza la recuperación. Pero cuando los NPLs alcanzan una magnitud considerable podrían verse desbordadas con estas gestiones. Por ello, en ocasiones ceden la gestión y la propiedad de sus carteras de NPLs a terceros. En algunos países, sin embargo, existen restricciones a la transferencia de la propiedad o de la gestión de créditos a agentes que no cuenten con licencia bancaria, lo que ralentiza la limpieza del balance de las entidades.

Además, el mercado secundario de NPLs dista mucho de ser un mercado perfectamente competitivo debido a las asimetrías de información entre los bancos y los compradores de NPLs. Así, muchos mercados de NPLs son markets for lemons donde únicamente se intercambian los préstamos de peor calidad o donde no existen transacciones.

A pesar de esta desventaja informativa, algunos agentes han conseguido desarrollar la capacidad para llevar a cabo una adecuada valoración de las carteras de NPLs. Pero el desarrollo de este expertise conlleva unos elevados costes que actúan como una barrera de entrada para potenciales inversores en NPLs. De este modo, los actuales compradores de NPLs cuentan con un cierto poder de monopsonio que se plasma en los elevados descuentos sobre el valor nominal que suelen exigir a la hora de adquirir NPLs de las entidades. Por ello, todas las medidas encaminadas a reducir las imperfecciones informativas en el mercado de NPLs facilitarán a los bancos la limpieza de sus balances.

El poder de monopsonio puede contrarrestarse con la creación de grandes vendedores de NPLs como los «bancos malos» o sociedades de gestión de activos (asset management companies, AMCs). Las AMCs, además de permitir a las entidades deshacerse más rápidamente de sus NPLs, presentan una serie de ventajas adicionales. Por un lado, cuentan con una mayor capacidad para diferir las ventas en el tiempo y esperar un cambio de ciclo que permita recuperar el valor de los NPLs. Por otro, en cuanto que su objetivo único es la gestión de NPLs, pueden contar con medios y personal exclusivamente centrados en esta tarea aprovechando así posibles economías de escala.

Otra de las ventajas de las AMCs es su rol como catalizadores del mercado secundario de deuda distressed. Las ventas de estas sociedades permiten descubrir los precios de mercado de activos, para los que hasta entonces existían pocas transacciones. Esta información puede ser tomada como referencia por las entidades de crédito para ajustar el valor contable de sus NPLs y por los compradores para valorar futuras adquisiciones.

En cualquier caso, no puede obviarse que la creación de AMCs requiere un importante compromiso de fondos públicos. Por ello, el diseño de estas sociedades debe respetar una serie de reglas que garanticen una adecuada asunción de pérdidas por parte de las entidades beneficiadas por la cesión de los NPLs y minimicen los riesgos para el contribuyente.

En resumen, aunque el saneamiento de los balances bancarios es responsabilidad última de las entidades, existen tres categorías de $\square$ 
medidas con las que el sector público puede contribuir a este proceso: 1) medidas para el adecuado reconocimiento y valoración de los NPLs, 2) medidas para mejorar la eficiencia del marco concursal y 3) medidas para favorecer el desarrollo del mercado secundario de NPLs. Bajo este marco, a continuación, resumiremos las políticas adoptadas en España durante la crisis financiera y las iniciativas surgidas a nivel de la Unión Europea en fechas más recientes.

\subsection{La resolución de los NPLs en España}

En los albores de la crisis, la actuación de sector público en España se centró en la provisión de liquidez a las entidades en apuros, en la reestructuración de las entidades de crédito, sobre todo de las cajas de ahorro, y en el fortalecimiento de los niveles de recursos propios. No sería hasta 2010, y especialmente a partir de 2012, cuando el foco se dirige más específicamente hacia el problema de los NPLs.

\subsubsection{Medidas para el adecuado reconocimiento y valoración de los NPLS}

La Circular del Banco de España 3/2010 (CBE 3/2010) puede considerarse la primera medida dirigida específicamente a abordar el problema de los NPLs. Su objetivo fundamental era aumentar los niveles de cobertura de los NPLs y de los activos adjudicados.

Antes de la CBE 3/2010, el deterioro estimado de los NPLs se calculaba atendiendo a dos

4 Circular 3/2010, de 29 de junio, del Banco de España, a entidades de crédito, de modificación de la Circular 4/2004, de 22 de diciembre, sobre normas de información financiera pública y reservada, y modelos de estados financieros. tipos de calendarios que obligaban a que las provisiones alcanzasen el 100 por 100 de los NPLs en un plazo máximo de 24 meses si no existían garantías asociadas o de 6 años en caso de que si las hubiese. La CBE 3/2010 estableció un único calendario en el que las provisiones debían alcanzar el 100 por 100 del importe del NPL no cubierto por el valor ajustado de la garantía en 12 meses.

En cuanto a la cobertura de los adjudicados, la CBE 3/2010 establecía un calendario creciente de provisiones que llegaba hasta el 30 por 100 del valor de los inmuebles a partir del segundo año que este permaneciese en el balance de la entidad.

En febrero y mayo de 2012 se aprobaron los denominados «Decretos Guindos » 5 . El primero de ellos, el Real Decreto-ley 2/2012, establecía unos exigentes requerimientos de cobertura para el stock existente a 31 de diciembre de 2011 de préstamos dudosos y subestándar relacionados con el sector inmobiliario y de activos inmobiliarios adjudicados en pago de deudas. Así, a lo largo de 2012, las entidades estaban obligadas a contar con los siguientes niveles de provisiones:

- 60 por 100 para operaciones de financiación de suelo.

- 50 por 100 para operaciones de financiación de obra en curso.

- Entre un 25 y un 60 por 100 para los inmuebles adjudicados.

- 7 por 100 para los préstamos en situación normal relacionados con la financiación de suelo, construcción y promoción inmobiliaria.

5 Real Decreto-ley 2/2012, de 3 de febrero, de saneamiento del sector financiero, y Real Decreto-ley 18/2012, de 11 de mayo, sobre saneamiento y venta de los activos inmobiliarios del sector financiero. 
Adicionalmente, se aplicaba un recargo de capital del 7 por 100 para los activos problemáticos vinculados con el suelo y con la promoción en curso.

En mayo, el Real Decreto-ley 18/2012 añadió provisiones de entre el 7 por 100 y el 45 por 100 a los préstamos en situación normal relacionados con la construcción o la promoción inmobiliaria.

Como consecuencia de las medidas hasta ahora mencionadas, las entidades españolas llevaron a cabo entre 2008 y 2012 saneamientos por importe de $\mathbf{2 3 8 . 0 0 0 ~ m i l l o n e s ~ d e ~ e u r o s , ~}$ una cifra equivalente al 23 por 100 del PIB (Banco de España, 2017). De ellos, casi 100.000 millones de euros fueron realizados en 2012.

También en mayo de 2012 el Consejo de Ministros decidió someter al juicio de dos expertos independientes (Oliver Wyman y Roland Berger) la salud del sistema bancario. En julio, ya en el marco del Memorando de Entendimiento firmado por España y la Comisión Europea, se llevó a cabo un exhaustivo AQR en el que se analizaron más de 36 millones de préstamos y 8 millones de garantías (Banco de España, 2017). El ejercicio determinó unas necesidades de capital para la banca española de 55.900 millones de euros en un escenario adverso.

Desde septiembre de 2012, el Banco de España puso también el foco en las operaciones de refinanciación y reestructuración. Así, la Circular 6/2012 del Banco de España ${ }^{6}$ exigió la publicación de todas las operaciones refinanciadas y reestructuradas. Adicionalmente, en abril de 2013, el supervisor emitió unos criterios que debían regir estas operaciones y su

\footnotetext{
6 Circular n. $\%$ 6/2012, de 28 de septiembre, del Banco de España, a entidades de crédito, de modificación de la Circular 4/2004, de 22 de diciembre, sobre normas de información financiera pública y reservada, y modelos de estados financieros.
}

tratamiento contable. En general, se permitió la reclasificación como «riesgo normal» únicamente de aquellos prestatarios que hubiesen atendido sus compromisos durante un periodo mínimo de un año desde la refinanciación o reestructuración y de las operaciones en las que el principal se hubiese reducido en, al menos, un 10 por 100 (Banco de España, 2017). El aumento de los préstamos morosos de 17.000 millones de euros que tuvo lugar en la segunda mitad de 2013 es, en gran medida, atribuible a estas medidas.

Por último, entre las medidas nacionales adoptadas para la adecuada identificación y valoración de los NPLs podemos destacar la Circular 4/2016 del Banco de España ${ }^{7}$ que modificó el Anejo IX de la Circular 4/2004 sobre análisis y cobertura del riesgo de crédito. Las principales novedades de esta norma radican en la redefinición de las categorías de riesgo y en la promoción del uso de modelos internos para calcular las provisiones. Las entidades que no cuenten con capacidad para desarrollar estos modelos pueden utilizar las denominadas «soluciones alternativas», es decir, calendarios de provisiones que exigen una dotación creciente de las provisiones de los préstamos sin garantías (y de la parte de los préstamos con garantía no cubierta por esta) hasta alcanzar el 100 por 100 de cobertura tras 18 o 21 meses según la tipología del crédito. Con respecto a la norma anterior, el nuevo Anejo IX refuerza la cobertura exigida a los NPLs con menos de 6 meses de antigüedad y a los destinados a crédito al consumo y beneficia a los préstamos destinados a la adquisición de vivienda.

\footnotetext{
7 Circular 4/2016, de 27 de abril, del Banco de España, por la que se modifican la Circular 4/2004, de 22 de diciembre, a entidades de crédito, sobre normas de información financiera pública y reservada y modelos de estados financieros, y la Circular 1/2013, de 24 de mayo, sobre la Central de Información de Riesgos.
} 


\subsubsection{Medidas para mejorar la eficiencia del marco concursal}

Existen empresas que generan beneficios en su negocio ordinario pero arrastran un elevado volumen de deuda que no pueden devolver. En estos casos, la reestructuración de la deuda permite a la empresa seguir operando y generando riqueza y empleo. Sin embargo, cuando las empresas no son viables es esencial garantizar una liquidación que maximice la recuperación para los acreedores.

Entre 2013 y 2015 se adoptaron en España numerosas medidas encaminadas a mejorar la eficiencia del marco concursal. Siguiendo a Arnal y Rodríguez (2015) pueden identificarse tres frentes de actuación de las reformas: el fomento de los acuerdos preconcursales, la reforma del procedimiento concursal y la introducción de la figura de la segunda oportunidad.

En materia de acuerdos preconcursales existen dos figuras: los acuerdos de refinanciación y los acuerdos extrajudiciales de pago. Los primeros están concebidos fundamentalmente para empresas de mediano y gran tamaño (Arnal y Rodríguez, 2015). El Real Decreto-ley $4 / 2014^{8}$ promovía estos acuerdos a través de medidas orientadas a favorecer la extensión de los acuerdos a acreedores disidentes y a acreedores con garantías, y a proteger a los acreedores que proporcionan nueva financiación en el marco del acuerdo. Así, el Real Decreto-ley extiende del 50 al 100 por 100 la cuantía de la nueva financiación a la que se le concede la calificación de crédito contra la masa (el crédito situado en primer lugar en el orden de prelación en el cobro) durante un plazo de 2 años.

8 Real Decreto-ley 4/2014, de 7 de marzo, por el que se adoptan medidas urgentes en materia de refinanciación y reestructuración de deuda empresarial.
Con objeto de mejorar los procedimientos concursales se adoptó el Real Decreto-ley $11 / 2014^{9}$. Esta norma trata de mejorar tanto la fase de convenio como la fase de liquidación. De manera similar al Real Decreto-ley 4/2014, se reducen las mayorías necesarias para que el acuerdo alcanzado en la fase de convenio sea extensible a los acreedores disidentes. Además, la norma otorga derechos de voto a acreedores que hasta entonces no los ostentaban, como los acreedores que adquirían sus derechos de crédito después de la declaración del concurso (Arnal y Rodríguez, 2015).

Por lo que respecta a la fase de liquidación, el Real Decreto-ley 11/2014 fomenta la enajenación global de la empresa por entenderse que esta opción mejora la recuperabilidad de las deudas frente a la liquidación por partes. A tales efectos, se obliga al administrador concursal a realizar una doble valoración de la empresa: una con arreglo a criterios de liquidación y otra atendiendo al principio de empresa en funcionamiento. Además, se permite al adquirente subrogarse en los derechos y obligaciones de contratos de la empresa adquirida sin necesidad de consentimiento de las contrapartes.

Por último, el Real Decreto-ley $1 / 2015^{10}$ trata de corregir una asimetría existente entre empresas y personas físicas empresarias o consumidoras. Mientras que las primeras podían liquidarse y permitir a sus socios empezar de cero, las segundas arrastraban las deudas contraídas de por vida. Por ello, el citado Real Decreto-ley permitió liberar completamente de sus deudas a las personas físicas cuyo patrimonio se hubiese liquidado en fase concursal y que hubiesen cumplido un plan de pagos a $\triangle$

\footnotetext{
9 Real Decreto-ley 11/2014, de 5 de septiembre, de medidas urgentes en materia concursal.

10 Real Decreto-ley $1 / 2015$, de 27 de febrero, de mecanismo de segunda oportunidad, reducción de carga financiera y otras medidas de orden social.
} 
5 años para satisfacer los créditos contra la masa y los créditos con privilegio general.

\subsubsection{Medidas para favorecer el desarrollo del mercado secundario de NPLS}

A diferencia de otros países, en España no existen restricciones a la adquisición ni a la gestión de créditos por agentes sin licencia bancaria. Por ello, las medidas para la promoción del mercado secundario de NPLs se han instrumentado como objetivos secundarios de otras medidas.

Este es el caso de la Sociedad para la Gestión de Activos procedentes de la Reestructuración Bancaria (Sareb), cuyo objetivo inicial era limpiar de una vez los balances de las entidades con mayores problemas. A diferencia de estas, Sareb contaba con un plazo mayor (15 años) para repartir las posibles pérdidas que pudiesen aparecer y para esperar un cambio de tendencia en los precios inmobiliarios. Tras el traspaso de activos a Sareb, los bancos contaban con un mayor espacio en su balance para reanudar la concesión de crédito.

Pero, además, cuando los mercados de NPLs son muy ilíquidos, las sociedades de gestión de activos como Sareb pueden jugar un papel crítico en le descubrimiento de precios y así contribuir al desarrollo del mercado secundario de NPLs (Medina y Peresa, 2016).

Sareb fue creada mediante las disposiciones adicionales séptima a novena del Real Decreto-ley 24/2012 ${ }^{11}$ (posteriormente convalidado por la Ley $9 / 2012^{12}$ ) cuyo contenido se desarrolla por el Real Decreto 1559/2012 ${ }^{13}$.

\footnotetext{
11 Real Decreto-ley 24/2012, de 31 de agosto, de reestructuración y resolución de entidades de crédito.

12 Ley $9 / 2012$, de 14 de noviembre, de reestructuración y resolución de entidades de crédito.

13 Real Decreto 1559/2012, de 15 de noviembre, por el que se establece el régimen jurídico de las sociedades de gestión de activos.
}

En virtud de estas normas, en diciembre de 2012 y febrero de 2013, 9 entidades transfirieron a Sareb todos sus inmuebles adjudicados antes del 30 de junio de 2012 con valor neto contable superior a 100.000 euros, y todos los créditos a dicha fecha con valor neto contable superior a 250.000 euros y vinculados a la financiación de suelo o promociones inmobiliarias. Los activos se transfirieron al precio calculado por Oliver Wyman y Roland Berger en el test de estrés de 2012 y usando como suelo las provisiones exigidas por los Decretos Guindos.

Así, Sareb recibió más de 200.000 activos por un valor bruto de más de 107.000 millones de euros por los que pagó un importe de 50.781 millones de euros, lo que representó un recorte (haircut) medio de más del 50 por 100 . En contraprestación, las entidades cedentes recibieron títulos de deuda sénior de Sareb a 1, 2 y 3 años, avalados por el Tesoro. De esta forma, intercambiaban activos ilíquidos y de dudosa calidad por títulos descontables en las operaciones de política monetaria del Banco Central Europeo.

Con objeto de garantizar la no consolidación de la deuda de Sareb con la deuda pública, la Ley 9/2012 prohibía expresamente que la participación pública en el accionariado superase el 50 por 100. En concreto, el resto del pasivo de Sareb distinto a la deuda sénior estaba compuesto por 3.600 millones de euros de deuda subordinada convertible en capital, de la cual el Frob suscribió el 45,9 por 100, y 1.200 millones de euros de capital (45 por 100 suscrito por el Frob).

Siguiendo el mandato de la Ley 9/2012, el Banco de España desarrolló en $2015^{14}$ el $\triangleright$

\footnotetext{
14 Circular 5/2015, de 30 de septiembre, del Banco de España, por la que se desarrollan las especificidades contables de la Sociedad de Gestión de Activos Procedentes de la Reestructuración Bancaria, SA.
} 
régimen contable que debía seguir Sareb en la valoración de sus activos. Este régimen sería ajustado a finales de 2016 mediante el Real Decreto-ley 4/2016 ${ }^{15}$.

Adicionalmente, Sareb está sometida a una triple supervisión. En primer lugar, el Banco de España se encarga de la supervisión de su actividad cotidiana. En segundo lugar, una Comisión de Seguimiento vigila el cumplimiento de los objetivos generales de Sareb, con especial énfasis en el proceso de desinversión y amortización de la deuda avalada. Esta Comisión está integrada por cuatro miembros: uno nombrado por el Ministerio de Economía y Empresa, que preside la Comisión, otro por el Ministerio de Hacienda, otro por el Banco de España, que ejerce de secretario, y otro por la Comisión Nacional del Mercado de Valores. La Comisión de Seguimiento se reúne al menos trimestralmente y remite a las Cortes Generales semestralmente un informe sobre la evolución de Sareb.

Por último, un experto independiente elabora anualmente el denominado «Informe Independiente de Cumplimiento» que tiene como finalidad evaluar la idoneidad de la actividad de Sareb para alcanzar los objetivos para los que fue constituida.

\subsection{La resolución de los NPLs en la Unión Europea}

Podemos considerar que no es hasta julio de 2016 cuando comienzan a adoptarse medidas específicas para abordar el problema de los NPLs a nivel de la Unión Europea con la constitución del Subgrupo de NPLs del Comité

15 Real Decreto-ley 4/2016, de 2 de diciembre, de medidas urgentes en materia financiera. de Servicios Financieros con el mandato de analizar la situación de los NPLs en la UE y proponer medidas para reducirlos. En junio de 2017 el Subgrupo publicó un informe que constaba de dos partes fundamentales: en la primera de ellas se analizaba el problema de los NPLs y sus implicaciones para la estabilidad financiera y económica y se realizaba una breve descripción de las medidas adoptadas en varios países. La segunda parte proporcionaba recomendaciones de política económica que se agrupaban en cuatro grandes áreas: mejorar las herramientas de gestión de NPLs de las entidades, reformas de los marcos de insolvencias, desarrollar el mercado secundario de NPLs y promover la restructuración del sector bancario.

En julio de 2017, el informe del Subgrupo recibió el respaldo del Ecofin. Además, atendiendo a las recomendaciones del informe, el Consejo adoptó el Plan de acción para abordar el problema de los préstamos dudosos en el sector bancario ${ }^{16}$. Dicho plan contenía numerosos mandatos a las instituciones que, al igual que en el caso español, podemos agrupar en tres áreas: 1) medidas para el adecuado reconocimiento y la valoración de los NPLs, 2) medidas para mejorar la eficiencia del marco concursal y 3) medidas para favorecer el desarrollo del mercado secundario de NPLs.

\subsubsection{Medidas para el adecuado} reconocimiento y la valoración de los $N P L S$

Entre las medidas adoptadas a nivel de la UE en esta materia podemos destacar dos: la $\triangle$

16 http://www.consilium.europa.eu/en/press/press-releases/2017/ 07/11/conclusions-non-performing-loans/ 
CUADRO 1

CALENDARIO PROVISIONES COMISIÓN EUROPEA

\begin{tabular}{|c|c|c|c|c|}
\hline \multirow{2}{*}{ Antigüedad } & \multicolumn{2}{|c|}{ NPLs } & \multicolumn{2}{|c|}{ Otras NPEs } \\
\hline & Parte no garantizada & Parte garantizada & Parte no garantizada & Parte garantizada \\
\hline Cobertura mínima después de 1 año & $35 \%$ & $5 \%$ & $28 \%$ & $4 \%$ \\
\hline Cobertura mínima después de 2 años & $100 \%$ & $10 \%$ & $80 \%$ & $8 \%$ \\
\hline Cobertura mínima después de 3 años & & $17,5 \%$ & & $14 \%$ \\
\hline Cobertura mínima después de 4 años & & $27,5 \%$ & & $22 \%$ \\
\hline Cobertura mínima después de 5 años & & $40 \%$ & & $32 \%$ \\
\hline Cobertura mínima después de 6 años & & $55 \%$ & & $44 \%$ \\
\hline Cobertura mínima después de 7 años & & $75 \%$ & & $60 \%$ \\
\hline Cobertura mínima después de 8 años & & $100 \%$ & & $80 \%$ \\
\hline
\end{tabular}

denominada propuesta de prudential backstops de la Comisión Europea ${ }^{17}$ y la Adenda a la Guía sobre NPLs del Banco Central Europeo (BCE) ${ }^{18}$.

La propuesta de prudential backstops de la Comisión se ha instrumentado como un reglamento que modifica el actual Reglamento de Requisitos de Capital cuyo ámbito objetivo de aplicación son todos los préstamos concedidos a partir del 15 de marzo de 2018 que se tornen non-performing. Para estos préstamos se establecen unos niveles mínimos de cobertura crecientes en función del tiempo que lleven declarados como non-performing y de si cuentan o no con garantías (Cuadro 1).

Estos niveles de cobertura habrán de dotarse con provisiones, en la medida que lo permita el marco contable, y con deducciones de capital en caso de que las provisiones sean insuficientes.

Por su parte, la Adenda del BCE fue publicada el pasado 15 de marzo. La Adenda complementa la Guía sobre NPLs ${ }^{19}$ publicada en marzo de 2017 que establecía, entre otras, la obligación de las entidades de crédito con

17 Proposal for a Regulation of the European Parliament and of the Council on amending Regulation (EU) No 575/2013 as regards minimum loss coverage for non-performing exposures.

18 Addendum to the ECB Guidance to banks on nonperforming loans: Prudential provisioning backstop for non-performing exposures. Marzo 2018.

19 Guidance to banks on non-performing loans. Marzo 2017. altos niveles de NPLs de presentar al supervisor un plan de reducción anual no vinculante. Al igual que la propuesta de prudential backstops, la Adenda tiene por objetivo prevenir la acumulación excesiva de NPEs sin provisionar en los balances de los bancos. También a semejanza de la propuesta de la Comisión, se definen unos niveles mínimos de cobertura que el supervisor espera que tengan las NPEs generadas a partir del 1 de abril de 2018 (con independencia de cuando se haya originado el préstamo) en función de su antigüedad en el balance de las entidades y de la existencia o no de garantías, si bien en este caso no se distingue entre NPLs y otras NPEs (Cuadro 2).

Si la suma de las provisiones contables y las deducciones de capital aplicadas por la entidad son inferiores a las expectativas del supervisor y el supervisor considera injustificadas las diferencias, podrá tener en cuenta este elemento a la hora de aplicar medidas adicionales de supervisión.

Por tanto, mientras que los niveles de cobertura exigidos por la propuesta de la Comisión son un requerimiento que todas las entidades deberán cumplir (medida de Pilar 1), las coberturas exigidas por el BCE constituyen una herramienta más a la hora de exigir medidas de Pilar 2. $\square$ 
CUADRO 2

CALENDARIO PROVISIONES BCE

\begin{tabular}{|c|c|c|}
\hline Antigüedad & Parte no garantizada & Parte garantizada \\
\hline Cobertura mínima después de 2 años & $100 \%$ & \\
\hline Cobertura mínima después de 3 años & & $40 \%$ \\
\hline Cobertura mínima después de 4 años & & $55 \%$ \\
\hline Cobertura mínima después de 5 años & & $70 \%$ \\
\hline Cobertura mínima después de 6 años & & $85 \%$ \\
\hline Cobertura mínima después de 7 años & & $100 \%$ \\
\hline
\end{tabular}

\subsubsection{Medidas para mejorar la eficiencia del marco concursal}

En noviembre de 2016, antes de que se aprobase el Plan de Acción para hacer frente a los préstamos dudosos, se presentó la propuesta de Directiva sobre marcos de reestructuración preventiva, segunda oportunidad y medidas para aumentar la eficacia de los procedimientos de condonación, insolvencia y reestructuración, que, al cierre de este artículo, aún se encontraba en negociación.

La propuesta persigue dos objetivos fundamentales. Por un lado, aspira a reducir el número de liquidaciones de empresas viables mediante la agilización de los procedimientos de reestructuración y, por otro, pretende facilitar la condonación de las deudas pendientes a los empresarios que hubiesen terminado un concurso en liquidación (segunda oportunidad).

Para favorecer la adopción de planes de reestructuración el texto garantiza la continuidad de la actividad del deudor mediante la suspensión de las ejecuciones y de la apertura de procedimientos de insolvencia durante las negociaciones del plan. Además, se otorga mayor protección a la financiación concedida a la empresa durante estas negociaciones.

Para garantizar la segunda oportunidad, se establecen principios mínimos que garanticen, en un plazo máximo de 3 años, la condonación a los empresarios de la deuda viva remanente tras un concurso finalizado en liquidación.

Por último, para aumentar la eficiencia de los procesos de reestructuración, los concursos de acreedores y la condonación de deudas, se fijan normas mínimas en materia de experiencia, designación y supervisión de los administradores concursales.

Ya en marzo de 2018, en el marco del Plan de Acción de NPLs, la Comisión presentó la propuesta de directiva sobre gestores de créditos, compradores de créditos y recuperación de garantías. Con objeto de incrementar la eficiencia de los procedimientos de recuperación de deudas con garantías, se establece la figura de la Ejecución Extrajudicial Acelerada de Garantías (AECE).

La AECE es un mecanismo que puede ser incorporado voluntariamente por las partes firmantes de un préstamo siempre que el deudor no sea una persona física no empresaria y la garantía del préstamo no sea su vivienda habitual. En caso de impago de la deuda, los Estados miembros deben poner a disposición de los acreedores alguna de las tres siguientes vías extrajudiciales para ejecutar la garantía: la subasta pública de dicha garantía, la venta privada o la apropiación por el deudor. 


\subsubsection{Medidas para favorecer el desarrollo del mercado secundario de NPLs}

Para promover el desarrollo del mercado secundario de NPLs, se han adoptado tres grandes medidas a nivel de la UE: la ya mencionada propuesta de Directiva sobre gestores de créditos, compradores de créditos y recuperación de garantías, las plantillas de NPLs de la EBA y la guía para la creación de «bancos malos» (AMCs) nacionales.

Además del AECE, la propuesta de Directiva sobre gestores de créditos, compradores de créditos y recuperación de garantías contiene disposiciones para eliminar las barreras innecesarias a la actividad de gestión de créditos (servicing) y a la compra de créditos por entidades no bancarias.

Así, se permite a los gestores de crédito (servicers) operar en cualquier país de la UE, siempre que hayan sido autorizados en algún Estado miembro. Para obtener esta autorización, los servicers deberán contar con buena reputación, no podrán encontrarse en situación concursal y deberán contar con procedimientos para garantizar el respeto de los derechos de los acreedores.

Por su parte, los compradores de créditos que no cuenten con licencia bancaria podrán adquirir créditos en cualquier país de la UE, siempre que empleen a servicers o entidades de crédito autorizadas en la UE para gestionar los créditos adquiridos.

Con el objetivo de reducir las asimetrías de información en el mercado de NPLs y la barrera a la entrada que supone contar con capacidad analítica suficiente para valorar una cartera de NPLs, la EBA publicó en diciembre de 2017 dos plantillas de uso voluntario para las entidades: la NPL screening template y la NPL transaction template (NPL templates). La primera proporciona, de forma estratificada, la información que es habitualmente requerida para realizar un sondeo de mercado, mientras que la segunda proporciona información detallada préstamo a préstamo.

Por último, la guía de la Comisión Europea para la creación de sociedades de gestión de activos (AMC blueprint) pretende ser una guía práctica para la constitución de «bancos malos» nacionales.

Para ello, la Comisión recomienda que, antes de la creación de la AMC, los NPLs y sus garantías estén perfectamente documentados, para lo cual recomienda utilizar las NPL templates. Adicionalmente, se considera oportuno llevar a cabo un test de estrés o una revisión de la calidad de los activos (AQR) con objeto de conocer el verdadero perímetro de activos que deben ser transferidos a la AMC.

Según la Comisión, los activos que se transfieran deberían ser homogéneos ya que, si bien una AMC puede presentar importantes economías de escala, las economías de alcance no son tan claras. Además, considera a los NPLs garantizados por inmuebles comerciales como idóneos para ser transferidos, pero duda de la conveniencia de transferir préstamos concedidos a hogares y garantizados por inmuebles residenciales por sus implicaciones sociales. Asimismo, las AMCs también estarían en una buena posición para gestionar NPLs sin garantías concedidos a grandes empresas y los inmuebles adjudicados de las entidades de crédito. Una vez que los activos se encuentren en propiedad de la AMC, deberán someterse al menos a una valoración anual.

Un aspecto de especial relevancia es la determinación del precio de transferencia. Si este es superior al valor de mercado de los activos, se considerará que existe ayuda del Estado y, para que esta sea legal, el precio de transferencia $\square$ 


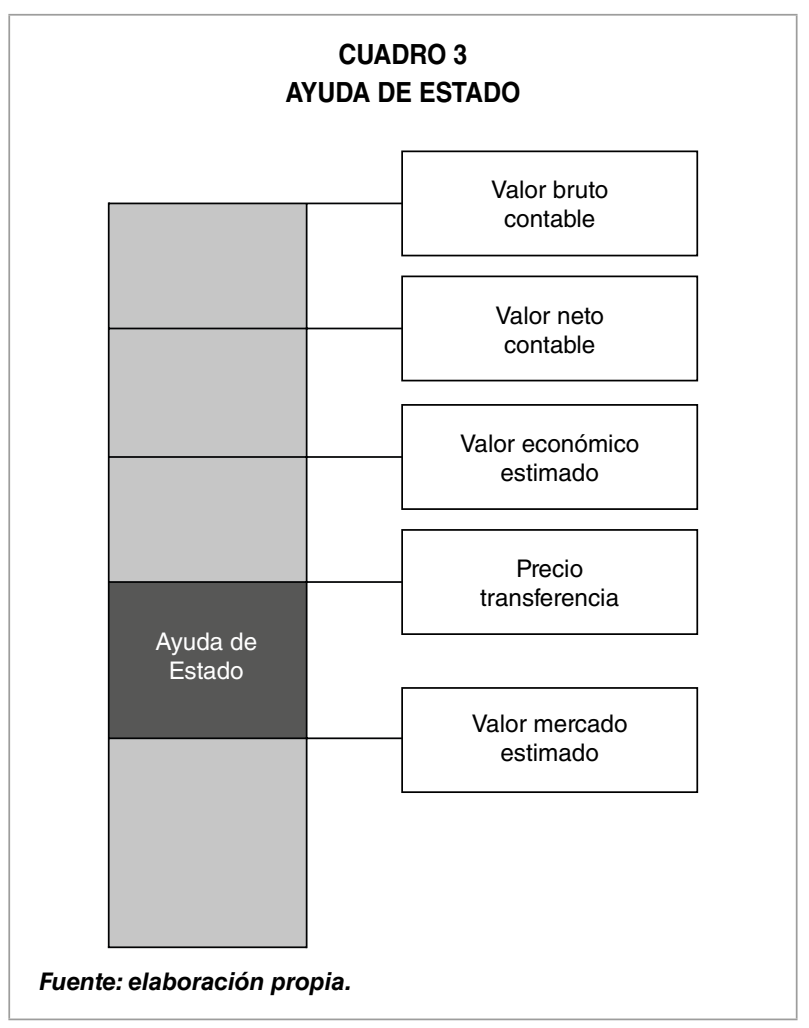

no podrá ser superior al valor económico estimado de los activos.

$\mathrm{Si}$, además, la transferencia a la AMC tiene lugar en el contexto de la resolución de una entidad de crédito, la constitución de la AMC deberá producirse con cargo al Fondo de Resolución y no podrá tener lugar hasta que al menos el 8 por 100 del pasivo de la entidad haya sido amortizado o convertido en capital (bailinado).

A la hora de establecer la AMC, el blueprint aconseja que, para operar con una mayor flexibilidad, esta no cuente con licencia de entidad de crédito ni de gestora de fondos y que no tenga naturaleza de agencia pública. No obstante, se considera esencial que esté sometida a una adecuada supervisión. Además, se recomienda establecer como único objetivo de la AMC la maximización del valor recuperado en un estricto límite temporal.

En cuanto a la estructura del pasivo, el blueprint sugiere que los activos recibidos se abonen en forma de bonos emitidos por la AMC con garantía del Estado y que, a su vez, dicha garantía se retribuya a un precio de mercado. Adicionalmente, la AMC debe contar con un nivel de capital suficiente para absorber las pérdidas que puedan originarse en los momentos iniciales de actividad. Según el blueprint, parte de ese capital debería estar en manos de las entidades cedentes de activos para que asuman parte del riesgo de la AMC.

\section{Conclusiones}

La resolución del problema de los NPLs debe basarse en tres pilares fundamentales. En primer lugar, las entidades deben identificar adecuadamente los NPLs que mantienen en su balance y provisionarlos de tal manera que su valor contable sea un fiel reflejo del importe recuperable. Sin embargo, en ocasiones, las entidades tienden a posponer estas tareas, por lo que una adecuada supervisión de las prácticas contables resulta clave.

En segundo lugar, aquellos créditos dudosos concedidos a prestatarios cuya actividad sea considerada viable deberían ser reestructurados, mientras que los que han sido concedidos a acreedores no viables deberían ser liquidados. Para maximizar los importes recuperados, es esencial contar con un marco concursal ágil y eficiente.

Por último, aquellas entidades que no cuenten con el tamaño o la experiencia suficiente para gestionar un abultado volumen de NPLs podrían ceder la gestión o la propiedad de estos activos a terceros especializados. En algunos casos, la creación de un «banco malo» que concentre en una única sociedad un gran volumen de NPLs permite aprovechar las economías de escala existente en la gestión de $\triangle$ 
estos activos. Además, es muy importante contar con un mercado secundario de NPLs eficiente, donde el margen bid-ask sea reducido y las ventas no supongan una elevada transferencia de valor de los bancos a los compradores.

Medidas como los Decretos Guindos, las diversas reformas concursales que tuvieron lugar entre 2013 y 2015 o la creación de Sareb han situado a España a la vanguardia de la resolución del problema de los NPLs.

A nivel europeo, el Plan de Acción para hacer frente a los préstamos dudosos supone el marco sobre el que se están articulando medidas que no solo buscan reducir los actuales niveles de NPLs, sino también prevenir su futura acumulación. Recientemente, varios Estados miembros han condicionado los avances en la Unión Bancaria a la reducción de los actuales niveles de NPLs. De este modo, el Plan de Acción constituye una pieza esencial de la arquitectura financiera de la UE.

\section{Bibliografía}

[1] AIYAR, S.; BERGTHALER, W.; GARRIDO, J. M.; ILYNA, A.; JOBST, A.; KANG, K.; KOVTUM, D.; LIU, Y.; MONAGHAN, D. y MORETTI, M. (2015). A Strategy for Resolving Europe's Problem Loans.

[2] ARNAL, J. y RODRÍGUEZ, S. (2015). Modificaciones y posibilidades legislativas recientes para impulsar la financiación a la empresa.

[3] BANCO CENTRAL EUROPEO (2017). Guidance to banks on non-performing loans.

[4] BANCO CENTRAL EUROPEO (2018). Addendum to the ECB Guidance to banks on nonperforming loans: Prudential provisioning backstop for non-performing exposures.

[5] BANCO DE ESPAÑA (2010). «Circular 3/2010, de 29 de junio, a entidades de crédito, de modificación de la Circular 4/2004, de 22 de diciembre, sobre normas de información financiera pública y reservada, y modelos de estados financieros». Boletín Oficial del Estado, n. ${ }^{\circ} 169,13$ de julio.

[6] BANCO DE ESPAÑA (2012). "Circular n.ㅇ 6/2012, de 28 de septiembre, a entidades de crédito, de modificación de la Circular 4/2004, de 22 de diciembre, sobre normas de información financiera pública y reservada, y modelos de estados financieros». Boletín Oficial del Estado, n. $-237,2$ de octubre.

[7] BANCO DE ESPAÑA (2016). «Circular 4/2016, de 27 de abril, por la que se modifican la Circular 4/2004, de 22 de diciembre, a entidades de crédito, sobre normas de información financiera pública y reservada y modelos de estados financieros, y la Circular 1/2013, de 24 de mayo, sobre la Central de Información de Riesgos». Boletín Oficial del Estado, n. $.0110,6$ de mayo.

[8] BANCO DE ESPAÑA (2017, mayo). Informe sobre la crisis financiera y bancaria en España, 2008-2014. Disponible en: https:// www.bde.es/f/webbde/Secciones/ Publicaciones/OtrasPublicaciones/Fich/ InformeCrisis_Completo_web.pdf

[9] BANCO DE ESPAÑA (2018, mayo). Boletín Estadístico del Banco de España. Disponible en: https://www.bde.es/bde/es/secciones/informes/boletines/Boletin_Estadist/

[10] COMISIÓN EUROPEA (2016). Proposal for a Directive on Insolvency, Restructuring and Second Chance.

[11] COMISIÓN EUROPEA (2018, march). AMC Blueprint.

[12] COMISIÓN EUROPEA (2018, march). Proposal for a Directive of the European Parliament and of the Council on credit servicers, credit purchasers and the recovery of collateral.

[13] COMISIÓN EUROPEA (2018, march). Proposal for a Regulation of the European Parliament and of the Council on amending Regulation (EU) No 575/2013 as regards minimum loss coverage for non-performing exposures.

[14] CONSEJO EUROPEO Y CONSEJO DE LA UNIÓN EUROPEA (2017, julio). Conclusiones del Consejo «Plan de acción para hacer frente a los préstamos dudosos en Europa». Bruselas. Disponible en: $h t t p: / / w w w . c o n s i l i u m . e u r o p a . ~ D$ 


\section{LA RESOLUCIÓN DEL PROBLEMA DE LOS PRÉSTAMOS MOROSOS EN ESPAÑA Y EN LA UE}

eu/es/press/press-releases/2017/07/11/ conclusions-non-performing-loans/

[15] EUROPEAN BANKING AUTHORITY (2014, July). EBA Final draft Implementing Technical Standards on Supervisory reporting on forbearance and non-performing exposures under article 99(4) of Regulation (EU) No 575/2013. Londres. Disponible en: https:// www.eba.europa.eu/documents/10180/ 449824/EBA-ITS-2013-03+Final+draft+ITS+o $n+$ Forbearance+and+Non-performing +exposures.pdf/a55b9933-be43-4cae-b8729184c90135b9

[16] EUROPEAN BANKING AUTHORITY (2016, July). EBA report on the dynamics of non-performing exposures in the EU banking sector. Londres. Disponible en: https://www.eba.europa.eu/documents/10180/1360107/ $E B A+$ Report+on+NPLs.pdf

[17] EUROPEAN BANKING AUTHORITY (2018, July). EBA risk dashboard - data as of Q1 2018. Londres. Disponible en: http://www.eba. europa.eu/documents/10180/2282718/ Risk+Dashboard+-+data+as+of+Q1+2018. pdf

[18] EUROPEAN CENTRAL BANK (2017, March). Guidance to banks on non-performing loans. Frankfurt. Disponible en: https://www.bankingsupervision.europa.eu/ecb/pub/pdf/guidance_on_npl.en.pdf

[19] EUROPEAN CENTRAL BANK (2018, March). Addendum to the ECB Guidance to banks on non-performing loans: supervisory expectations for prudential provisioning of non-performing exposures. Frankfurt. Disponible en: $h t-$ tps://www.bankingsupervision.europa.eul ecb/pub/pdf/ssm.npl_addendum_201803. en.pdf

[20] EUROPEAN CENTRAL BANK (2018, April). Supervisory Banking Statistics - Fourth quarter 2017. Disponible en: https://www. bankingsupervision.europa.eu/ecb/pub/pdf/ssm.supervisorybankingstatistics_fourth_quarter_2017_201804.en.pdf

[21] MEDINA CAS, S. Y PERESA, I. (2016, September). What Makes a Good 'Bad Bank'? The Irish, Spanish and German Experience.

[22] MEMORANDO DE ENTENDIMIENTO ENTRE LA COMISIÓN EUROPEA Y ESPAÑA (2012). Boletín Oficial del Estado, n.․ 296, 10 diciembre.
[23] PODER LEGISLATIVO DE ESPAÑA (2012, 15 de noviembre). Ley $9 / 2012$, de 14 de noviembre, de reestructuración y resolución de entidades de crédito. Boletín Oficial del Estado, n. -275.

[24] PODER LEGISLATIVO DE ESPAÑA (2012, 4 de febrero). «Real Decreto-Ley 2/2012, de 3 de febrero, de saneamiento del sector financiero». Boletín Oficial del Estado, n. 30.

[25] PODER LEGISLATIVO DE ESPAÑA (2012, 12 de mayo). «Real Decreto-Ley 18/2012, de 11 de mayo, sobre saneamiento y venta de los activos inmobiliarios del sector financiero". Boletín Oficial del Estado, n. 114.

[26] PODER LEGISLATIVO DE ESPAÑA (2012, 31 de agosto). «Real Decreto-Ley 24/2012, de 31 de agosto, de reestructuración y resolución de entidades de crédito». Boletín Oficial del Estado, n.으. 210.

[27] PODER LEGISLATIVO DE ESPAÑA (2012, 16 de noviembre). «Real Decreto 1559/2012, de 15 de noviembre, por el que se establece el régimen jurídico de las sociedades de gestión de activos». Boletín Oficial del Estado, n. .276.

[28] PODER LEGISLATIVO DE ESPAÑA (2014, 8 de marzo). «Real Decreto-Ley 4/2014, de 7 de marzo, por el que se adoptan medidas urgentes en materia de refinanciación y reestructuración de deuda empresarial». Boletín Oficial del Estado, n.․58.

[29] PODER LEGISLATIVO DE ESPAÑA (2014, 6 de septiembre). «Real Decreto-Ley 11/2014, de 5 de septiembre, de medidas urgentes en materia concursal». Boletín Oficial del Estado, n. .217.

[30] PODER LEGISLATIVO DE ESPAÑA (2015, 28 de febrero). «Real Decreto-Ley 1/2015, de 27 de febrero, de mecanismo de segunda oportunidad, reducción de carga financiera y otras medidas de orden social». Boletín Oficial del Estado, n. .51.

[31] PODER LEGISLATIVO DE ESPAÑA (2016, 3 de diciembre). «Real Decreto-Ley 4/2016, de 2 de diciembre, de medidas urgentes en materia financiera». Boletín Oficial del Estado, n. -292.

[32] PRICE WATERHOUSE COOPER (2016, mayo). Nuevo Anejo IX. Análisis Comparativo con el Anejo IX vigente. Disponible en: $D$ 
Juan Antonio García Hernández

http://www.clubgestionriesgos.org/wp-content/uploads/PWC-Comparativa-NuevoAnejo-IX-Versi\%C3\%B3n-para-Imprimir.pdf

COMMITTEE (2017, may). Report of the FSC Subgroup on Non-Performing Loans. Bruselas. Disponible en: $h$ ttp://data.consilium. europa.eu/doc/document/ST-9854-2017-INIT/

en/pdf 